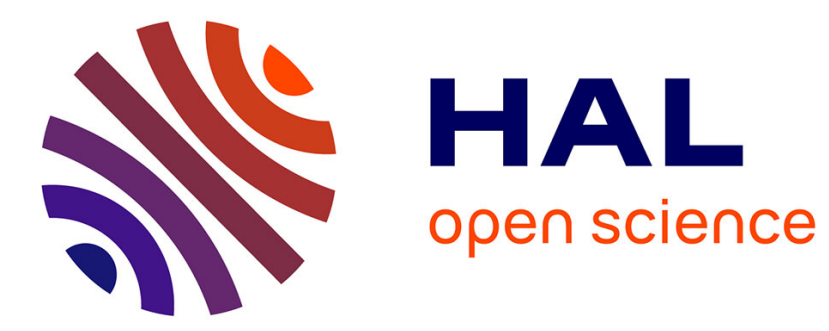

\title{
Effect of fibre orientation on mechanical properties of the laminated polymer composites subjected to out-of-plane high strain rate compressive loadings
}

\author{
Mostapha Tarfaoui, S. Choukri, A. Neme
}

\section{- To cite this version:}

Mostapha Tarfaoui, S. Choukri, A. Neme. Effect of fibre orientation on mechanical properties of the laminated polymer composites subjected to out-of-plane high strain rate compressive loadings. Composites Science and Technology, 2007, 68 (2), pp.477. 10.1016/j.compscitech.2007.06.014 . hal00498990

\section{HAL Id: hal-00498990 \\ https://hal.science/hal-00498990}

Submitted on 9 Jul 2010

HAL is a multi-disciplinary open access archive for the deposit and dissemination of scientific research documents, whether they are published or not. The documents may come from teaching and research institutions in France or abroad, or from public or private research centers.
L'archive ouverte pluridisciplinaire HAL, est destinée au dépôt et à la diffusion de documents scientifiques de niveau recherche, publiés ou non, émanant des établissements d'enseignement et de recherche français ou étrangers, des laboratoires publics ou privés. 


\section{Accepted Manuscript}

Effect of fibre orientation on mechanical properties of the laminated polymer composites subjected to out-of-plane high strain rate compressive loadings

M. Tarfaoui, S. Choukri, A. Neme

PII: S0266-3538(07)00255-2

DOI: 10.1016/j.compscitech.2007.06.014

Reference: CSTE 3746

To appear in: Composites Science and Technology

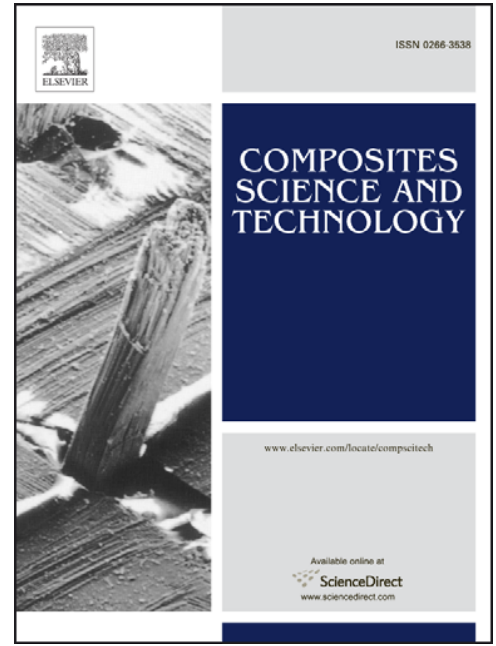

Received Date: $\quad 16$ March 2007

Revised Date: $\quad 4$ June 2007

Accepted Date: $\quad 10$ June 2007

Please cite this article as: Tarfaoui, M., Choukri, S., Neme, A., Effect of fibre orientation on mechanical properties of the laminated polymer composites subjected to out-of-plane high strain rate compressive loadings, Composites Science and Technology (2007), doi: 10.1016/j.compscitech.2007.06.014

This is a PDF file of an unedited manuscript that has been accepted for publication. As a service to our customers we are providing this early version of the manuscript. The manuscript will undergo copyediting, typesetting, and review of the resulting proof before it is published in its final form. Please note that during the production process errors may be discovered which could affect the content, and all legal disclaimers that apply to the journal pertain. 


\title{
EFFECT OF FIBRE ORIENTATION ON MECHANICAL PROPERTIES OF THE LAMINATED POLYMER COMPOSITES SUBJECTED TO OUT-OF-PLANE HIGH STRAIN RATE COMPRESSIVE LOADINGS
}

\author{
M. Tarfaoui ${ }^{1 *}$, S. Choukri ${ }^{2}$, A. Neme ${ }^{1}$ \\ ${ }^{1}$ ENSIETA / MSN, 29806 Brest, France \\ ${ }^{2}$ EMI, Département Génie Mécanique, Rabat, Maroc
}

\section{Abstract}

This study examines the mechanical characteristics of composite structures evolving with the strain rates. The purpose of this work is the use of Split Hopkinson Pressure Bar (SHPB) for the dynamic characterization of the fibre orientation and strain rate effects in particular on the mechanical behaviour, the damage and the strength of a glass/epoxy composite, very much used in the naval domain. It is also a question of understanding the microscopic mechanisms leading to the damage and the failure of material and of quantifying their evolution with the strain rate. The materials examined in the study were all manufactured using the infusion process. E-glass fibres were impregnated with a low viscosity epoxy resin. Samples, of cubic geometry, are tested in the thickness direction for seven fibre orientations, $0^{\circ}, \pm 20^{\circ}, \pm 30^{\circ}, \pm 45^{\circ}, \pm 60^{\circ}, \pm 70^{\circ}$ and $90^{\circ}$

Keywords: E glass/epoxy composites, dynamic response, fibre orientation, strain rate, damage.

\section{Introduction}

The composite materials with organic matrix found important applications in the shipbuilding industries. New applications of the composites are identified, including

\footnotetext{
* Corresponding author. Tel.: +33-630-499-748; fax: +33-298-348-730.

E-mail address: tarfa omo@ensieta.fr

Postal address: 2 rue Fran ço is Verny 29806 Brest - FRANCE
} 
their current and potential use in superstructures, platforms and some large military equipment, such as destroyers and aircraft carriers. The mechanical characteristics of these materials are well known for static loading, they are likely to evolve with the strain rate [1-4].

The behaviour of structures subject to impact has been of interest to many scientists for purposes of design as well as developing constitutive models of the materials tested [5-6]. The study of the composite materials behaviour at high strain rates is still relatively new and reliable data on strain rate effects is very scarce. Although the problem of obtaining reliable data is accentuated by difficulties encountered in designing and conducting of impact tests on composites [7]. The qualitative relationship between the dynamic constitutive response and the dynamic damage evolution for composites at high strain rates are still far from understanding. To investigate the ratedependent constitutive relations of materials at high strain rates, the Split Hopkinson Pressure Bar (SHPB) technique has been extensively accepted [8]. The experience of the use of SHPB for the investigation of metals led to the adaptation of this technique for the laminated polymer composites characterization at medium strain rates. Significant efforts has been made to examine the high strain rate behaviour using the split Hopkinson bar, of more brittle materials such as composites and ceramics, to measure dynamic response of materials under varying loading conditions [9-12]. Most recently, the study conducted by Ho sur et al. [13] presents the effect of in-plane off-axis testing of an 8-harness satin weave carbon fabric/SC15 composite specimens. Specimens were tested in the in-plane direction of $0^{\circ}, 15^{\circ}, 30^{\circ}, 45^{\circ}, 60^{\circ}, 75^{\circ}$, and $90^{\circ}$ in a range of strain rates from 1092 to $2425 \mathrm{~s}^{-1}$. From this study it was noted that the high strain rate tested specimens showed considerable increase in the stress to failure and 
stiffness of the composite compared to the quasistatic loaded specimens. Depending on the fibre orientation of the specimens, the ultimate strength and strain varied considerably and exhibited a nonlinear stress-strain response that increases with angle up to $45^{\circ}$. Tsai and Sun [14] have reported the difference between tensile and compressive behaviours in a unidirectional glass fibre-reinforced composite, and developed a nonlinear rate-dependent viscoplasticity model to characterize its compressive stress-strain relationship. Many different models [15-17] have been developed to predict failure stress and modes in composites subjected to quasi-static loading. However, few criteria have been developed and experimentally validated for high strain rate loading.

In this study, specimens of glass/epoxy composite used in marine applications were subjected to a static and dynamic compression loading. Quasi-static tests were conducted on an Instron universal machine to evaluate the elastic properties and quasistatic response, while the split-Hopkinson pressure bar (SHPB) is used for dynamic tests. Samples were tested in the thickness direction. The fibre orientations of the samples were $0^{\circ}, \pm 20^{\circ}, \pm 30^{\circ}, \pm 45^{\circ}, \pm 60^{\circ}, \pm 70^{\circ}$ and $90^{\circ}$. Stress-strain curves at increasing strain rates were obtained for different cases. However, no experimental data for the intermediate range of strain rates between $\left(80 \mathrm{~s}^{-1}\right.$ to $\left.300 \mathrm{~s}^{-1}\right)$ was obtained, because the Instron universal testing machine and the SHPB employed in the experimental tests are designed respectively for low and high strain rates. Off-axis composites and angle ply laminates exhibited significant nonlinear and strain dependent behaviour. Finally experimental observations enable us to draw up the history of the dynamic damage in the specimens according the fibre orientation and strain rate evolution. 


\section{Material and specimens}

The material used in this study consists of 2400 Tex E-glass fibres impregnated with an epoxy matrix. The resin is a EPOLAM pre-polymer, EPOLAM 2020 hardener and 2020 accelerator from Axson. Glass fibres are commonly used for naval applications because of their high strength/mass ratio and their low cost compared to other reinforcements. The reinforcement consists of a plain weave fabric with $90 \%$ warp yarns and $10 \%$ weft yarns. Panels were made by infusion process and seven orientations are studied: $0^{\circ}, \pm 20^{\circ}, \pm 30^{\circ}, \pm 45^{\circ}, \pm 60^{\circ}, \pm 70^{\circ}$ and $90^{\circ}$. The square panels, $500 \times 500$ $\mathrm{mm}$, were cut into samples of the geometry which dimensions are shown in Table 1. The standard deviations are indicated in brackets. Laminate properties given in Table 2 are calculated by laminate theory expressions [18].

\section{Elastic properties}

Two types of static compression tests are used to obtain the elastic properties of the lamina. In-plane loading (IP), parallel to the plies plane; plane $(1,2)$, and out-of-plane loading (OP), according to the thickness; direction 3. Table 2 compares the elastic values of the characteristics drawn from relations of micromechanics with those resulting from experimental work.

One can note that the damage for out-of-plane loading case appears by a cracking along the diagonal of the cube, which means that cracking crossed the weft yarns which represent the weakest part of the fabric. On the other hand, the matrix cracks and delamination occur in the privileged interlaminar planes for in-plane loading, Figure 1. 


\section{Dyna mic tests}

The split Hopkinson bar test is the most commonly used method for determining material properties at high strain rates, Figure 2a. This technique of characterization, based on the response of a material to wave propagation for high strain rate from $100 \mathrm{~s}^{-1}$ to $5000 \mathrm{~s}^{-1}$, was improved by Kolsky [8].

The experimental set-up consists of (1) a stress generating system which is comprised of a split Hopkinson bars and the striker, (2) a specimen, (3) a stress measuring system made up of sensors (typically resistance strain gauges), and (4) a data acquisition and analysis system. The signals are treated with Maple Software package using Fast Fourier Transformation to obtain the evolution of the dynamic parameters: stress vs. strain, strain rate vs. time, incident and transmitted load and velocity at the interfaces input bar/sample and output bar/sample vs. time.

\subsection{Data processing procedure}

The specimens $[0]_{40},[ \pm 20]_{20},[ \pm 30]_{20},[ \pm 45]_{20},[ \pm 60]_{20},[ \pm 70]_{20}$ and $[90]_{40}$ were subjected to dynamic compression loading in the thickness direction. Nine different impact level were applied to the input bar by varying the pressure acting on the striker bar, from 0.5 to 1.6 by step of $0.1 / 0.2$ bar : $0.5,0.6,0.7,0.8,0.9,1.0,1.2,1.4$ and 1.6bar witch correspond to the impact velocities: $3.6,6.3,8.1,9.9,11.7,13.5,15.1,17.1$ and $18.9 \mathrm{~m} / \mathrm{s}$. Many processing schemes are necessary before obtaining stress, strain and strain rate in the specimen, namely the Fast Fourier Transform of the sampled signals and their transport from strain gauges location to the specimen loaded faces (Figure 1), under non dispersive hypothesis of the wave propagation in the bars. Figure 2 shows typical signals time variations and the stress/strain curve for a given strain rate. 


\subsection{Strain rate dependencies of dynamic mechanical properties}

Before launching the experimental study for dynamic case, it is necessary to be ensured of the tests reproducibility. For this objective, for each fibre orientation, a minimum of two tests was carried out at the same impact pressure to analyze dispersion. As figure 4 shows it, it is noted that dispersion is weak and that was checked for all the tests.

For out-of-plane (OP) tests, results for compressive strain rates between $200 \mathrm{~s}^{-1}$ and $2000 \mathrm{~s}^{-1}$ are obtained using SHPB. Figure 5 shows the evolution of the strain rate versus time. The maximum value is considered for the analysis of the experimental results.

The strain rate evolution is sensitive to the entry pressure in the chamber of compressed air P (impact pressure of the striker on the input bar), the loading direction and the sample lay-up (angle $\theta$ ). we will analyze that in detail in the following section.

For the results analysis and exploitation, we will be interested in the evolution of: in itial dynamic modulus $\left(\mathrm{E}_{\text {dynamic }}\right)$ witch is evaluated for the linear part of $\sigma=f(\varepsilon)$ curves for different $(\dot{\varepsilon})$, maximum stress $\left(\sigma_{\operatorname{Max}}\right)$, strain at maximum stress $\left(\varepsilon_{\sigma_{\operatorname{Max}}}\right)$ and total $\operatorname{strain}\left(\varepsilon_{\text {Max }}\right)$

In a concern of simplifying the graphic representations, the analyzed parameters: $E_{\text {dynamic }}, \sigma_{\operatorname{Max}}, \varepsilon_{\sigma_{\operatorname{Max}}}$ and $\varepsilon_{\text {Max }}$ will be given according to the impact pressure (P) and the fibre orientation $\theta$ (Teta). The evolution of $\dot{\varepsilon}$ is approximated by a quadratic equation, Figure 6. Table 3 gives the coefficients of this function.

Figure 7 gives the experimental curves in blue and the envelope surface. The evolution of $\dot{\varepsilon}$ follows two phases: a first phase $(0.5 \leq \mathrm{P} \leq 1.2$ bar $)$ where the increase is fast and the second phase where the variation is less marked. The fibre orientation has 
an effect on the strain rate evolution. Indeed, one notices on blue curves that the evolution of $\dot{\varepsilon}$ is relatively similar for samples $20 / 70,30 / 60$ and $45 / 45$ whereas for samples $0 / 90$ it is different.

Figure 8 give the evolution of the strain rate of [0/90], [20/70], [30/60] and [45/45] samples for 9 impact pressures. The appearance of a second peak is around $0.9 \mathrm{bar}$ for [0/90] and 1.4bar for the other orientation, Table 4. The dynamic behaviour for OP tests is dominated by compressive properties of the polymeric matrix and the damage is created for high impact pressure. The fibres orientation affects the initiation and propagation of damage. For undamaging tests, the fall of strain rate passes by negative values, which correspond to the springback in the sample. The glass/epoxy composite materials present a high strength on compressive dynamic loading for OP tests.

One can note that $[20 / 70]$ and [30/60] have similar dynamic response, Figure 9 . The unloading part of $\sigma=f(\varepsilon)$ curves indicates if there is plasticity or another damaging modes. The second peak of $\dot{\varepsilon}=\mathrm{f}(\mathrm{t})$ curves corresponds to the fall of stress in the sample. The dynamic behaviour of the various laminates is strongly affected by the strain rate and fibres orientation, Figure 10. For OP tests, there is always an increase in $E_{\text {dynamic }}, \sigma_{\text {Max }}$ and $\varepsilon_{\sigma_{\text {Max }}}$ with the increase in the impact pressure. There is not threshold effect for OP loading; the transitional pressure does not exist, Figure 11.

\section{Damage}

The damage tolerance is an important parameter for the use of composite materials in the technologically advanced sectors and in particular for military naval applications. This characterization passes by drawing up the history and the damage kinetics of material from initiation until the complete failure. Several techniques are used to 
examine the extent of damage. First, during the dynamic compression, High-speed photography and infrared camera were used to follow the damage in the samples. Frames taken in real time are used for illustrating the evolution of the damage. Impacted samples were inspected by optical techniques and fluorescent dye was applied to improve damage visualization. The damage can also be located by the presence of a second peak on the $\dot{\varepsilon}=f(t)$ curve. To the formation of this peak a fall of stress corresponds, Figure 10.

The first observation that one can make, for out-of-plane tests, is that material shows a greater strength. The damage appears only for the great impact pressures: $0.8 \mathrm{bar}$ for $\left[0 / 90^{\circ}\right]_{40}, 1.4-1.6$ bar for $\left(\left[20 / 70^{\circ}\right]_{20}\right.$ and $\left.\left[30 / 60^{\circ}\right]_{20}\right)$ and 1.4 bar for $\left[45 / 45^{\circ}\right]_{20}$. For this lower range of impact pressure there were only residual "plastic" deformations due to matrix cracks. One can also notice that the nature of the damage is strongly affected by the laminates orientation, Figure 11-12, witch still a parameter in improving also out of plane dynamic compressive strength. The multiplication of the microscopic cracks involves the catastrophic failure. The high strength recorded for 20/70 and 30/60 can be correlated with damaging modes observed and reported in figure 13. In fact for these specimens multiple mode fracture is depicted. As the strain rate increase more damage mechanism is involved; from matrix cracking to delamination with multiple paths to final fracture. For $0 / 90$ and $45 / 45$ specimens a dominant path is observed along the weakest link, respectively across weft yarns and plies interfaces, witch may explain the lower strength. The kinetics of damage for this direction of loading is strongly conditioned by the specimen's fibre orientations. Figure 13 summarizes the history of damaging modes for the various laminates. 


\section{Conclusion}

In this work, the high strain rate material response of $[0]_{40},[ \pm 20]_{20},[ \pm 30]_{20},[ \pm 45]_{20}$, $[ \pm 60]_{20},[ \pm 70]_{20}$ and $[90]_{40}$ E-glass/epoxy composite material systems was investigated. Samples were subjected to OP tests. The effects of fibre orientation and strain rates in a glass/epoxy composite material under compressive dynamic loading are examined. Moreover, a family of compressive stress-strain curves, as well as failure modes, at dynamic strain rates at a series of fibre orientation were determined. All of the stressstrain curves had similar shapes: an initial linear elastic portion followed by a nonlinear behaviour until failure. The stress-strain curves of the composite materials show that the material is strongly sensitive to fibre orientation at the same impact pressure: the initial modulus of elasticity, maximum failure stress, strain at maximum stress and the maximum strain are all dependent on fibre orientation and strain rates. The initiation and propagation of failure mechan is ms at different strain rates have been examined. The most pronounced effect of increasing the strain rate results in changes in the failure modes. Specimen fails by fibre kinking at low strain rates, with delamination and interfacial separation dominating the high strain rate failure regime. Off-axis composites and angle ply laminates exhibited significant nonlinear and strain dependent behaviour.

\section{References}

1. Bouette B., Cazeneuve C. and Oytana C. Effect of strain rate on interlaminar shear properties of carbon/epoxy composites. Composites Science and Technology, Volume 45, Issue 4, 1992, Pages 313-321.

2. Zhao H. and Gary G. An experimental investigation of compressive failure strength of fibre-reinforced polymer matrix composite plates under impact loading. Composites Science and Technology, Volume 57, Issue 3, 1997, Pages 287-292. 
3. Zhao H. Material behavior characterization using SHPB techniques, tests and simulations. Computers and Structures, 81, 1301-1310 (2003).

4. Fitoussi J., Meraghni F., Jendli Z., Hug G., Baptiste D. Experimental methodology for high strain-rates tensile behaviour analysis of polymer matrix composites. Composites Science and Technology, Volume 65, Issue 14, November 2005, Pages 2174-2188.

5. Hou J. P. and Ruiz C. Measurement of the properties of woven CFRP T300/914 at different strain rates. Composites Science and Technology, Volume 60, Issue 15, November 2000, Pages 2829-2834.

6. Gilat A., R.K. Golberg, G.D. Roberts. Experimental study of strain rate dependent behavior of carbon/epoxy composite. Composite Science and Technology, 62, 1469-1476 (2002).

7. Harding J. The Effect of High Strain Rate on Material Properties. Materials at High Strain Rate, ed. T. Z. Blazynski. Elsevier Applied Science, London \& New York, 1987.

8. Kolsky H. An investigation of the mechanical properties of materials at very high rates of loading. Proc. Phys. Soc. , 1949, Vol. 62B, 676-700.

9. Kumar P., A. Garg. and Argawal, B.D. Dynamic compressive behavior of unidirectional GFRP for various fiber orientations. Material letters, 1986, Volume 4, Issue 2, 111-116.

10. El-Habak A.M.A.. Mechanical behavior of woven glass fiber-reinforced composites under impact compression load. Composites, Volume 22, Issue 2, 1991, 129-134.

11. Harding J. Effect of strain rate and specimen geometry on the compressive strength of woven glass-reinforced epoxy laminates. Composites, Volume 24, Issue 4, 1993, 323-332.

12. Sierakowski R.L., G.E. Nevill. Dynamic compressive strength and failure of steel reinforced epoxy composites. Journal of Composite Materials. 1971, Vol. 5, 362-377.

13. Hosur MV, Alexander J, Vaidya UK, Jeslani S, Mayer A. Studies on the o.-axis high strain rate compression loading of satin weave carbon/epoxy composites. Computer and Structure 2004;63:75-85.

14. Tsai J, Sun CT. Constitutive model for high strain rate response of polymeric composites. Composite Science and Technology 2002;62:1289-97. 
15. Soden P., Hinton M., Kaddour A. Lamina properties, lay-up configurations and loading conditions for a range of fibre-reinforced composite laminates. Composite Science and Technology, Special issue on "Failure criteria in fibre reinforced polymer composites" part A, 1998;58(7):1011-1022.

16. Gotsis P. K., Chamis C. C. and Minnetyan L. Application of progressive fracture analysis for predicting failure envelopes and stress-strain behaviors of composite laminates: a comparison with experimental results. Composite Science and Technology, Special issue on "Failure criteria in fibre reinforced polymer composites" part B, 2002;62(12/13): 1545 1559.

17. Travis A. Bogetti, Christopher P. R. Hoppel, Vasyl M. Harik, James F. Newill and Bruce P. Burns. Predicting the nonlinear response and failure of composite laminates: correlation with experimental results. Composite Science and Technology, Special issue on "Failure criteria in fibre reinforced polymer composites" part C, 2004;62(3/4): 449-476.

18. Chamis, C.C. Simplified micromechanics equations for hygral, thermal, and mechanical properties. SAMPE Quarterly, 1984. 


\section{List of Figure headings}

Figure 1. Damage in static tests

Figure 2. Typical compressive split Hopkinson bar apparatus

Figure 3. Results of the application of FFT, OP test for $[ \pm 30 / \pm 60]$ specimen, $\mathrm{P}=1$ bar

Figure 4. Tests reproducibility - OP test, $\mathrm{P}=1.4$ bar

Figure 5. Strain rate evolution, OP test of $[ \pm 20 / \pm 70] \mathrm{P}=1.4$ bar

Figure 6. Strain rate versus impact pressure for OP tests

Figure 7. Strain rate evolution versus fibre orientation and impact pressure

Figure 8. Strain rate evolution versus impact pressure

Figure 9. Stress - Strain curves evolution versus strain rate

Figure 10. Evolution of the stress and strain curves versus time

Figure 11. $\mathrm{E}_{\text {dynamic }}, \sigma_{\mathrm{Max}}, \varepsilon_{\sigma_{\mathrm{Max}}}$ and $\varepsilon_{\text {Max }}$ versus $\mathrm{P}$ and $\theta$ for OP tests

Figure 12. Damage specimens for out-of-plane tests

Figure 13. Damaging modes for OP tests 


\section{List of tables}

Table 1. Geometry and fibre mass fraction of the samples, standard deviation in brackets

Table 2. Elastic properties of E-glass/epoxy lamina

Table 3. Coefficients of quadratic functions

Table 4. Critical impact pressure for appearance of second peak 


\section{ACCEPTED MANUSCRIPT}

\begin{tabular}{|c|ccccc|}
\hline Panel & $\begin{array}{c}\text { Thickness, } \\
(\mathbf{m m})\end{array}$ & $\begin{array}{c}\text { Surface } \\
\left(\mathbf{m m}^{2}\right)\end{array}$ & $\begin{array}{c}\text { void fraction } \\
(\%)\end{array}$ & $\begin{array}{c}\text { Stacking } \\
\text { sequence }\end{array}$ & $\begin{array}{c}\text { Fibre volume } \\
\text { Fraction }(\%)\end{array}$ \\
\hline A & $13.00(0.1)$ & $13 \times 13(0.2)$ & 9.26 & {$[0]_{40}$} & $53.5(0.5)$ \\
B & $12.52(0.3)$ & $13 \times 13(0.2)$ & 9.00 & {$[ \pm 20]_{20}$} & $54.0(0.5)$ \\
C & $13.00(0.1)$ & $13 \times 13(0.2)$ & 8.78 & {$[ \pm 30]_{20}$} & $55.0(0.5)$ \\
D & $12.78(0.2)$ & $13 \times 13(0.2)$ & 8.69 & {$[ \pm 45]_{20}$} & $54.3(0.5)$ \\
\hline
\end{tabular}

Table 1. Geometry and fibre mass fraction of the samples, standard deviation in brackets

\begin{tabular}{|l|ccccccccc|}
\hline Characteristics & $\begin{array}{c}\mathrm{E}_{1} \\
(\mathrm{MPa})\end{array}$ & $\begin{array}{c}\mathrm{E}_{2} \\
(\mathrm{MPa})\end{array}$ & $\begin{array}{c}\mathrm{E}_{3} \\
(\mathrm{MPa})\end{array}$ & $v_{12}$ & $v_{13}$ & $v_{23}$ & $\begin{array}{c}\mathrm{G}_{12} \\
(\mathrm{MPa})\end{array}$ & $\begin{array}{c}\mathrm{G}_{13} \\
(\mathrm{MPa})\end{array}$ & $\begin{array}{c}\mathrm{G}_{23} \\
(\mathrm{MPa})\end{array}$ \\
\hline Experimental & 46217 & 16086 & 9062 & 0.28 & 0.41 & 0.097 & 2224 & 3500 & 4540 \\
Rules law & 42030 & 14524 & 9130 & 0.31 & - & 0.01 & 3441 & 3273 & 4508 \\
\hline
\end{tabular}

Table 2. Elastic properties of E-glass/epoxy lamina

\begin{tabular}{|c|rccc|}
\hline OP Tests & $\mathbf{0}^{\circ} / \mathbf{9 0}^{\circ}$ & $\mathbf{2 0}^{\circ} / \mathbf{7 0}^{\circ}$ & $\mathbf{3 0}^{\circ} / \mathbf{6 0 ^ { \circ }}$ & $\mathbf{4 5}^{\circ} / \mathbf{4 5} \mathbf{O}^{\circ}$ \\
\hline$\alpha$ & -135.5 & -676.66 & -341.17 & -329.77 \\
$\beta$ & 1581 & 2444.9 & 1801.9 & 1585.9 \\
$\gamma$ & -336.33 & -830.42 & -560.75 & -34173 \\
\hline
\end{tabular}

Table 3. Coefficients of quadratic functions

\begin{tabular}{|c|cccc|}
\hline OP Tests & $\mathbf{0}^{\circ} / \mathbf{9 0}^{\circ}$ & $\mathbf{2 0 ^ { \circ } / \mathbf { 7 0 } ^ { \circ }}$ & $\mathbf{3 0}^{\circ} / \mathbf{6 0 ^ { \circ }}$ & $\mathbf{4 5}^{\circ} / \mathbf{4 5} \%$ \\
\hline $\mathrm{P}_{\mathrm{c}}$ (bar) & 0.9 & 1.6 & 1.6 & 1.4 \\
\hline
\end{tabular}

Table 4. Critical impact pressure for appearance of second peak 


\section{ACCEPTED MANUSCRIPT}

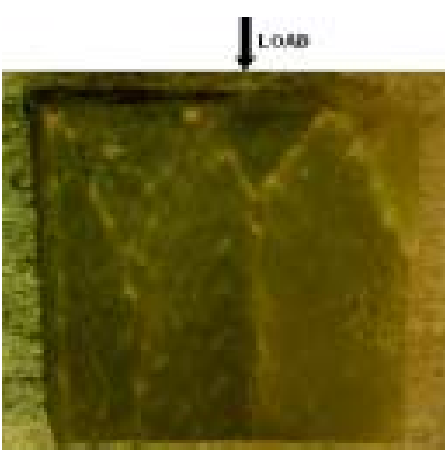

$[0]_{40}$ In-plane

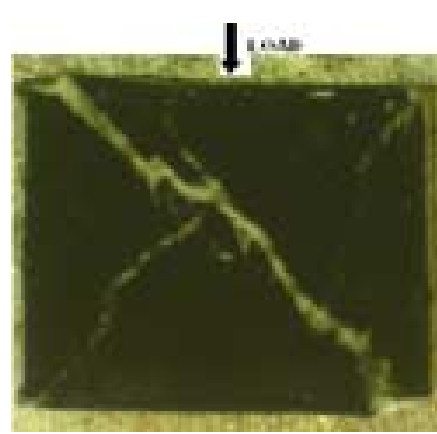

$[90]_{40}$ In-plane

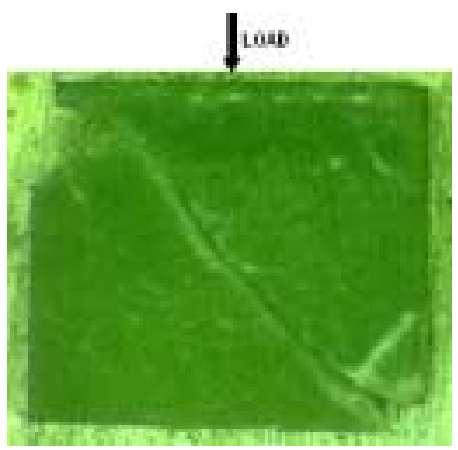

[0/90] ${ }_{40}$ Out-of-plane

Figure 1. Damage in static tests

(a)



(b)

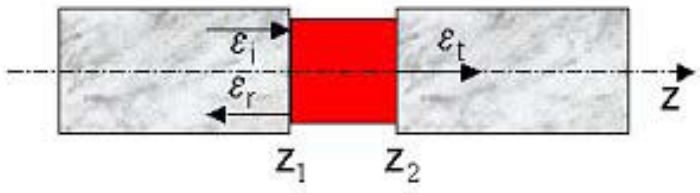

Figure 2. Typical compressive split Hopkinson bar apparatus 


\section{ACCEPTED MANUSCRIPT}
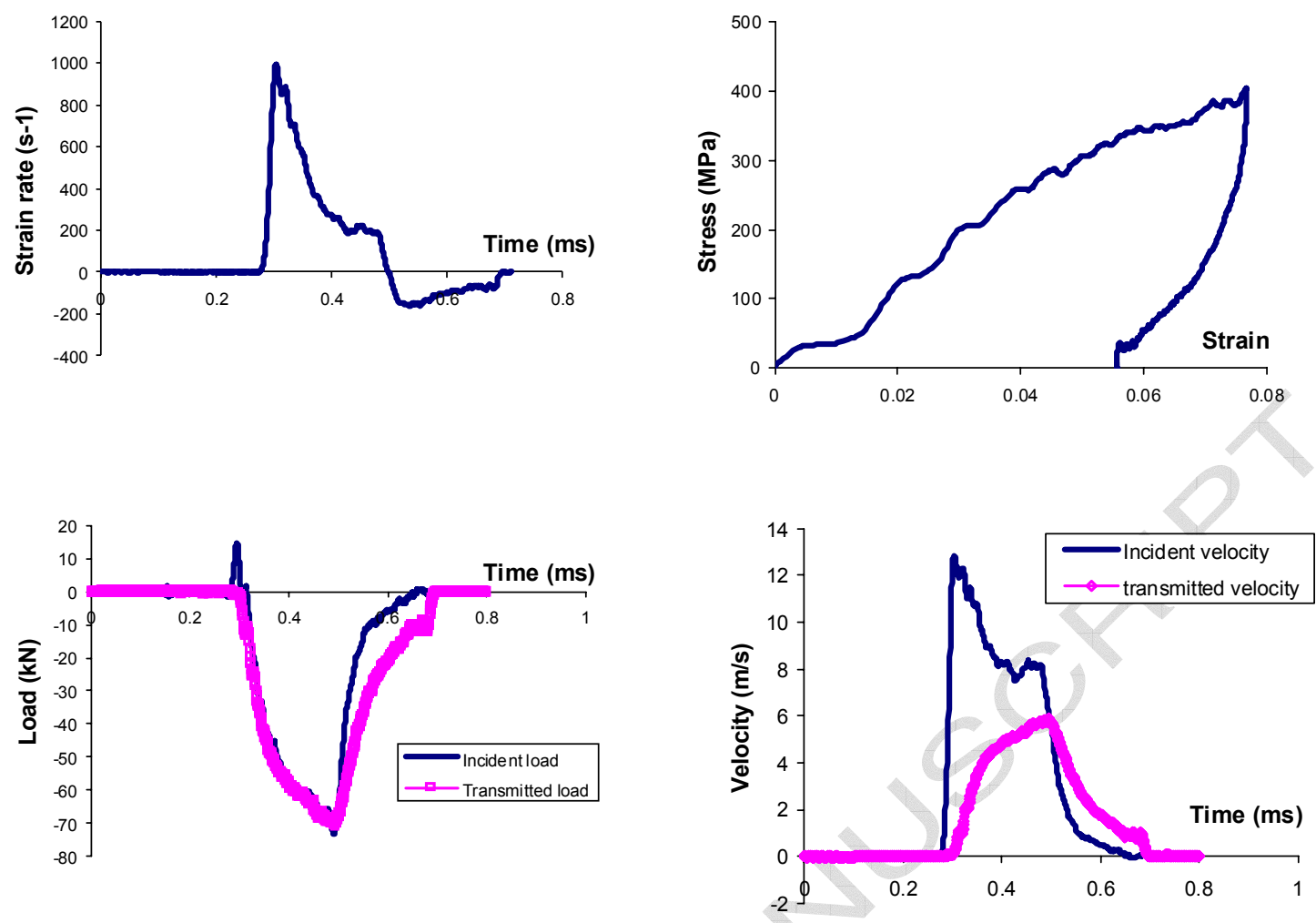

Figure 3. Results of the application of FFT, OP test for $[ \pm 30 / \pm 60]$ specimen, $\mathrm{P}=1$ bar

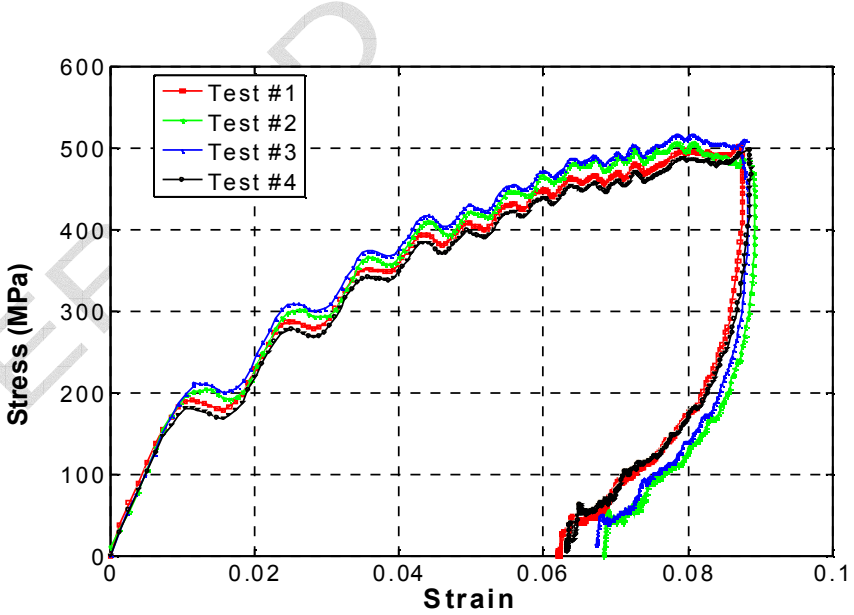

Figure 4. Tests reproducibility, $\mathrm{OP}$ test $\mathrm{P}=1.4 \mathrm{bar}$ 


\section{ACCEPTED MANUSCRIPT}

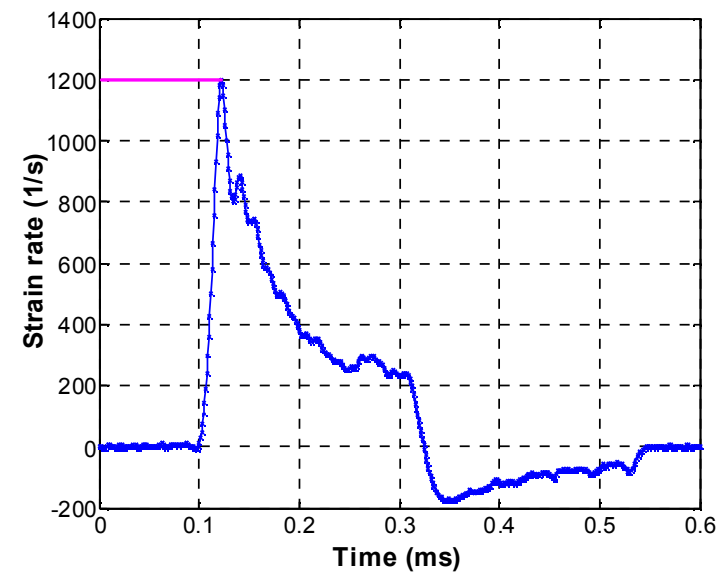

Figure 5. Strain rate evolution, OP test of $[ \pm 20 / \pm 70] \mathrm{P}=1.4$ bar

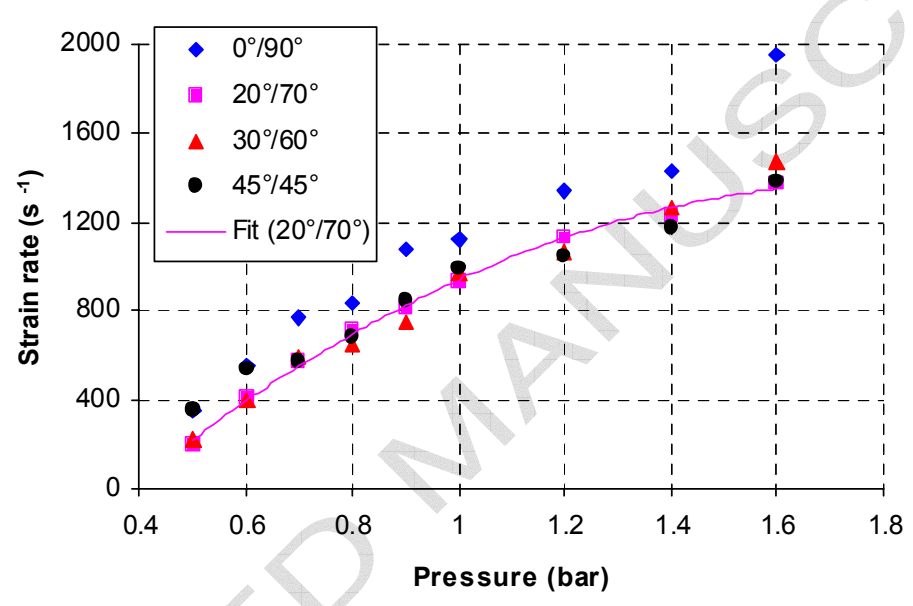

Figure 6. Strain rate versus impact pressure for OP tests

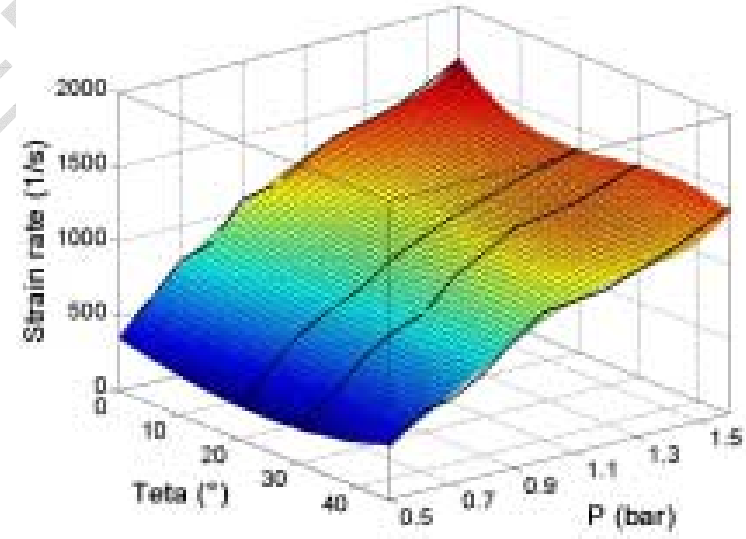

Figure 7. Strain rate evolution versus fibre orientation and impact pressure 


\section{ACCEPTED MANUSCRIPT}
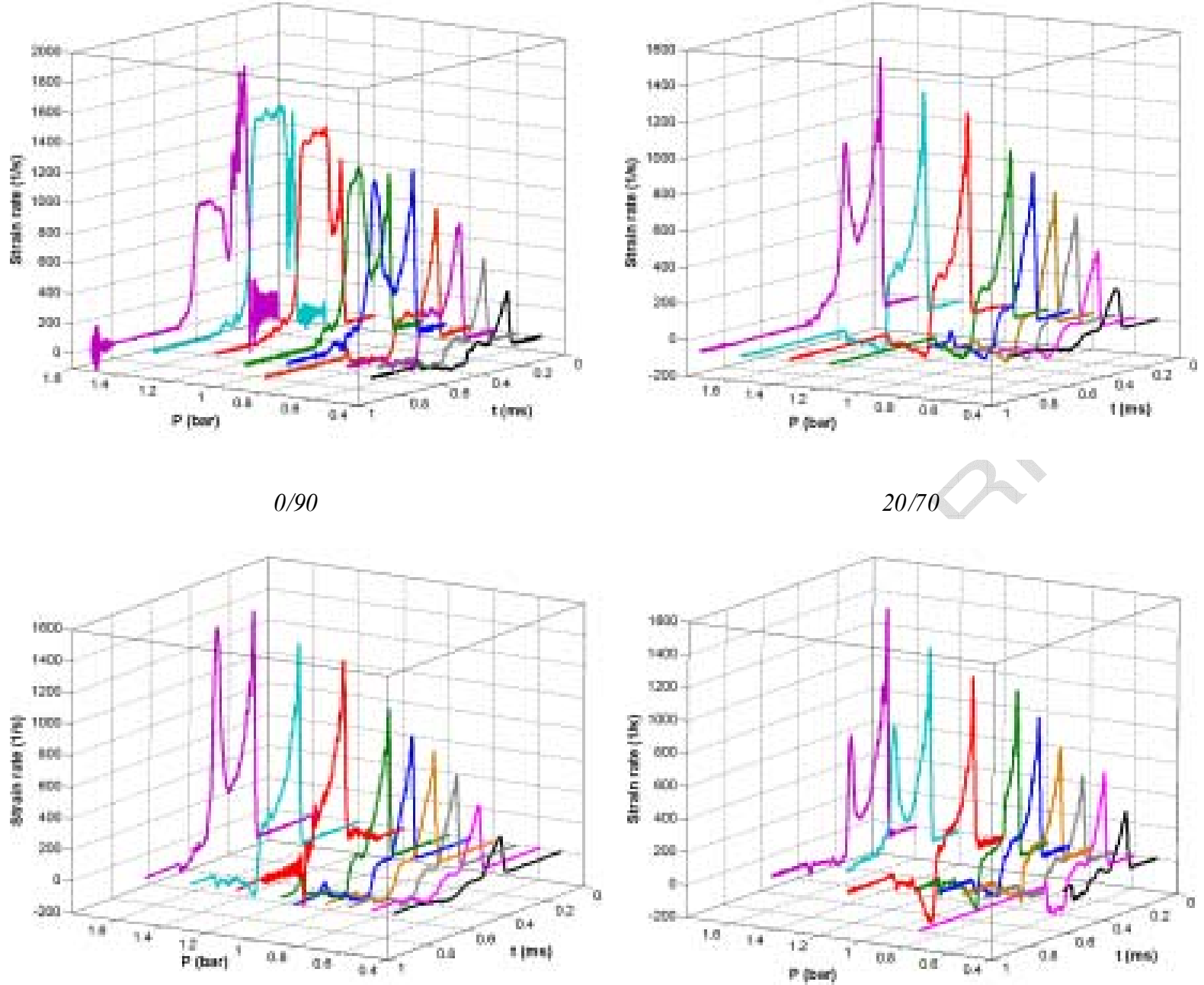

$30 / 60$

$45 / 45$

Figure 8. Strain rate evolution versus impact pressure 


\section{ACCEPTED MANUSCRIPT}

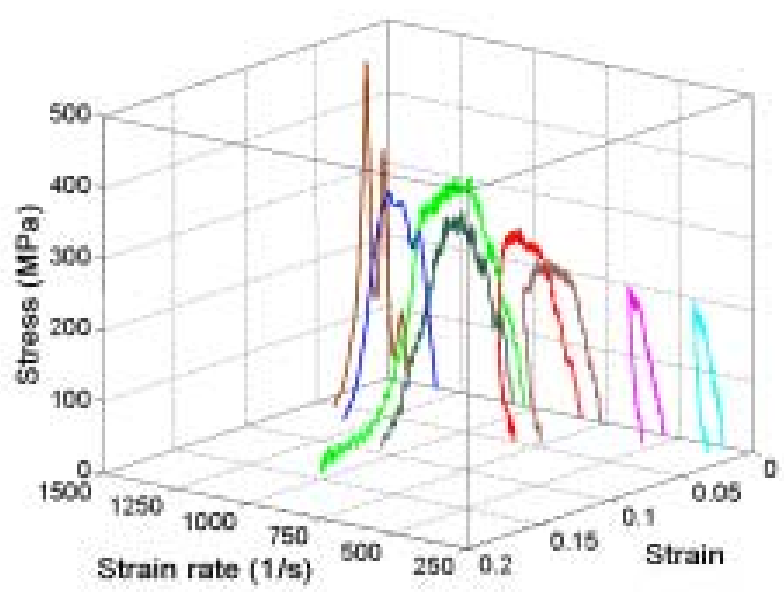

$0 / 90$

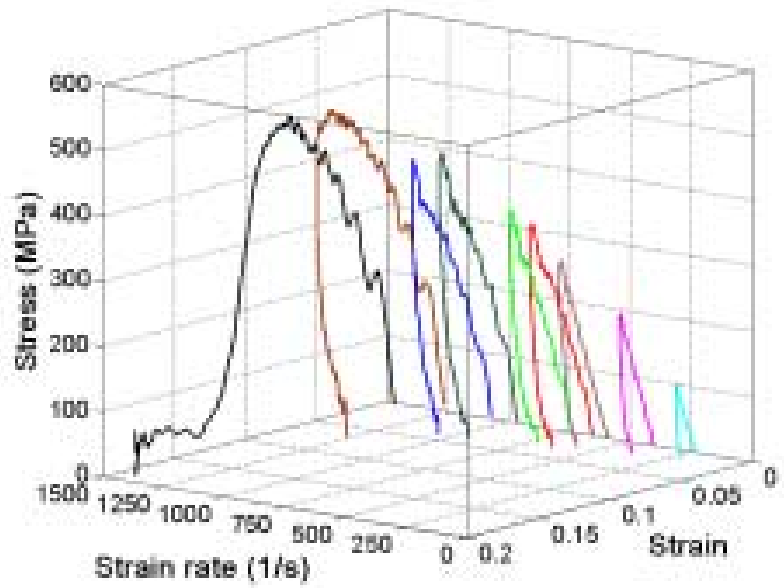

$30 / 60$

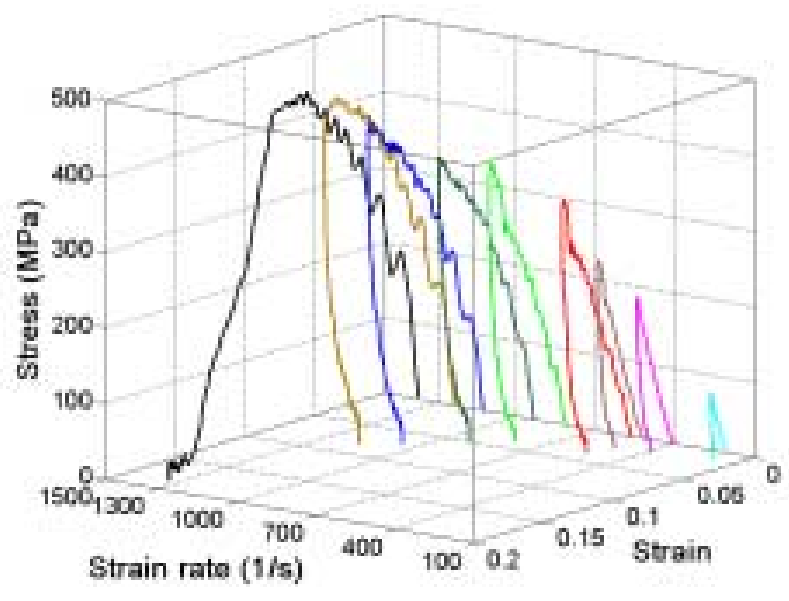

$20 / 70$

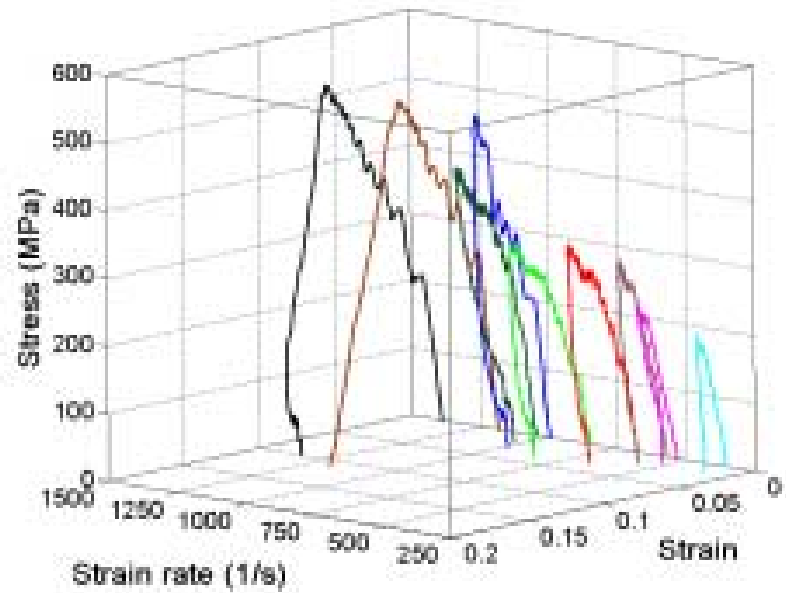

$45 / 45$

Figure 9. Stress - Strain curves evolution versus strain rate
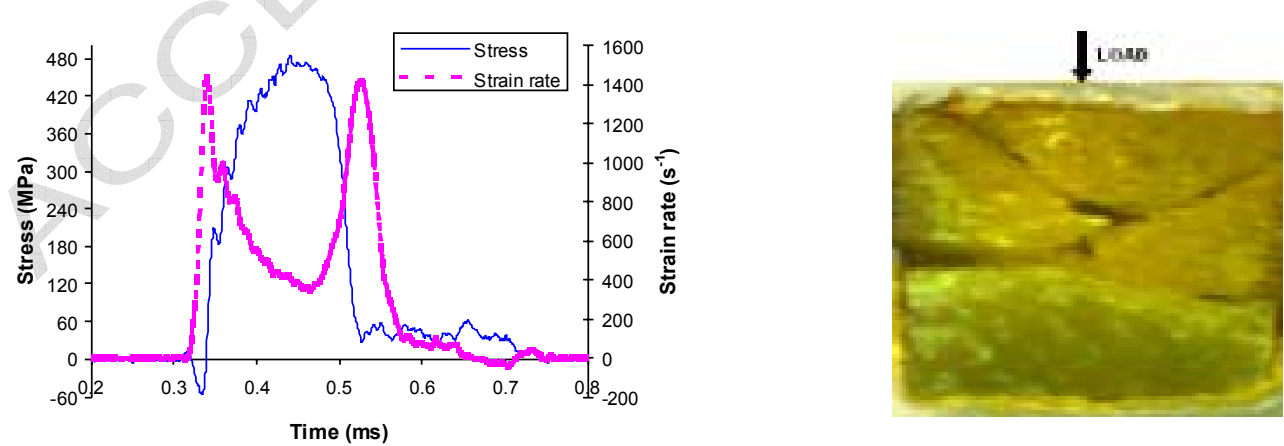

30/60, HP test, $P=1.6 \mathrm{bar}$

Figure 10. Evolution of the stress and strain curves versus time 


\section{ACCEPTED MANUSCRIPT}
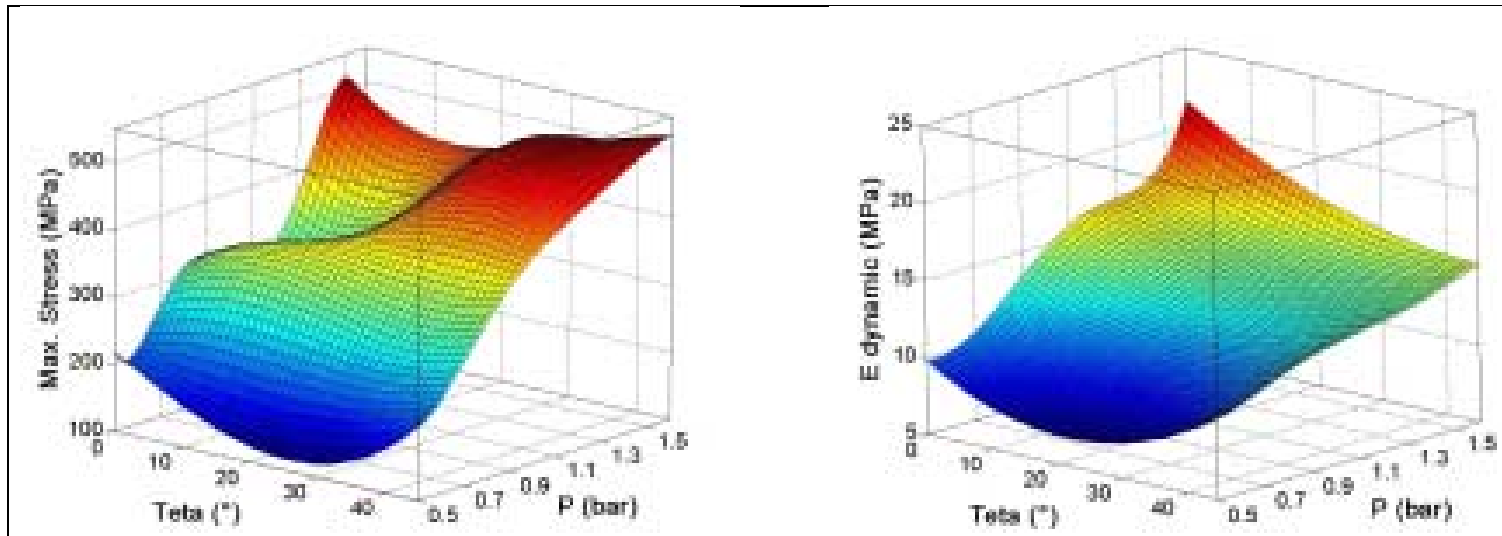

Maximum Stress
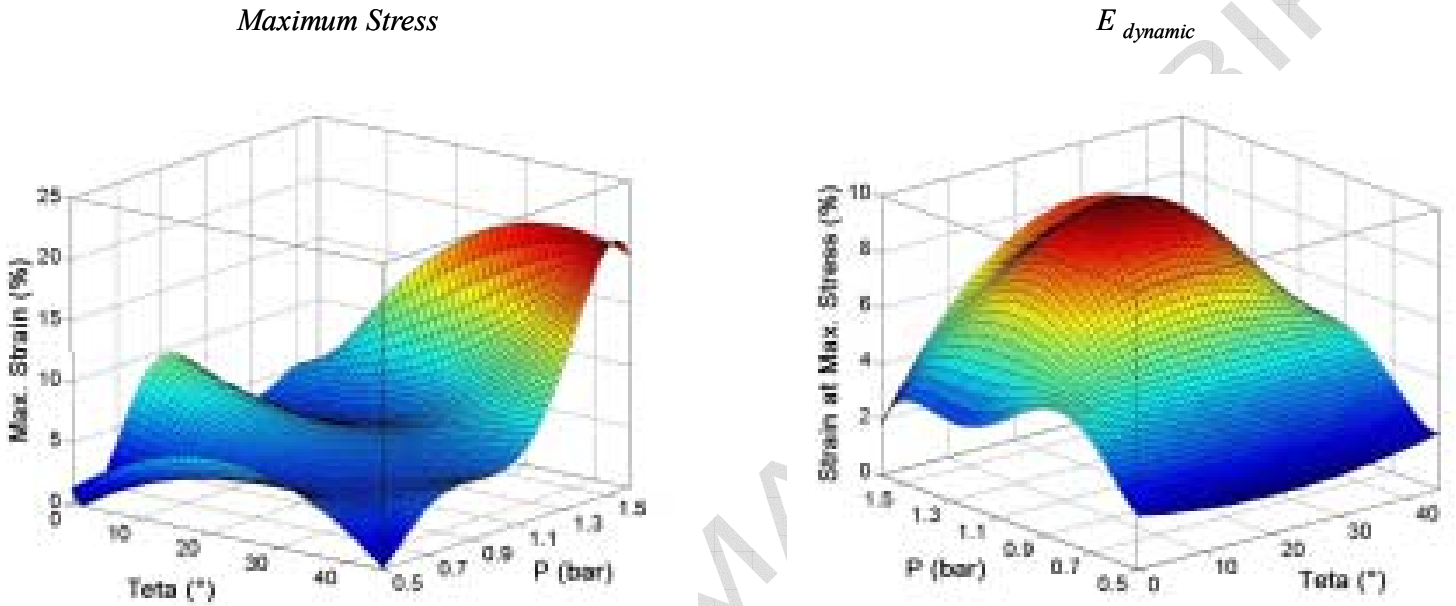

Strain at Max. stress

Figure 11. $\mathrm{E}_{\text {dynamic }}, \sigma_{\mathrm{Max}}, \varepsilon_{\sigma_{\operatorname{Max}}}$ and $\varepsilon_{\operatorname{Max}}$ versus $\mathrm{P}$ and $\theta$ for OP tests 


\section{ACCEPTED MANUSCRIPT}
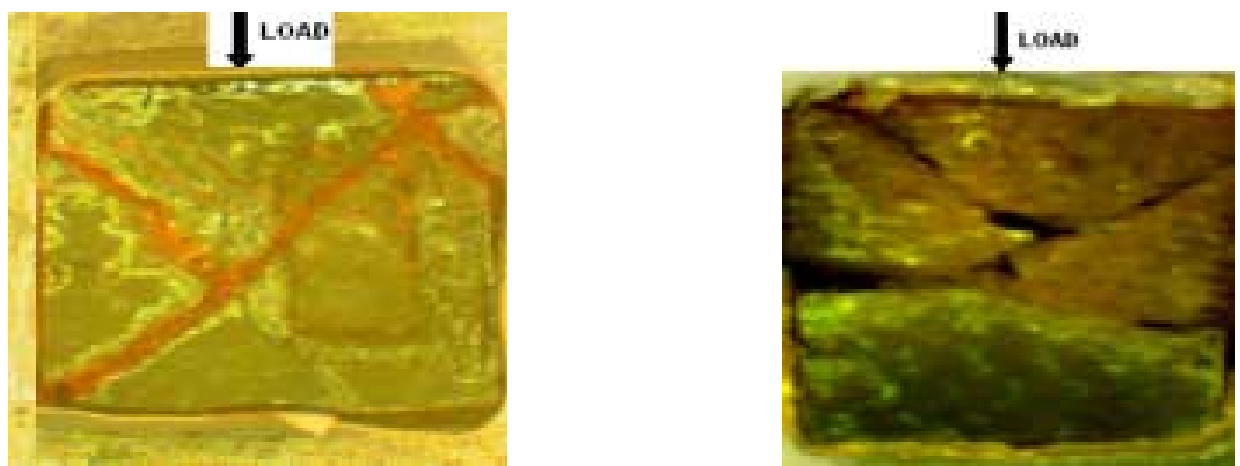

$[0]_{40}, P=1 \operatorname{bar}\left(\dot{\varepsilon}=1074 \mathrm{~s}^{-1}\right)$ $[ \pm 30]_{20}, P=1.6 \mathrm{bar}\left(\dot{\varepsilon}=1430 \mathrm{~s}^{-1}\right)$

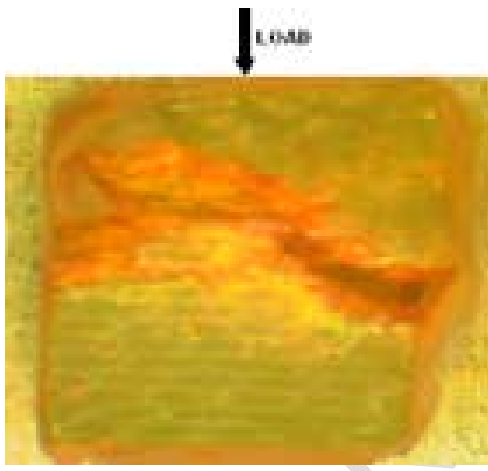

$[ \pm 45]_{20}, 1.4 \mathrm{bar}\left(\dot{\varepsilon}=1181 \mathrm{~s}^{-1}\right)$

Figure 12. Damage specimens for out-of-plane tests 


\section{ACCEPTED MANUSCRIPT}

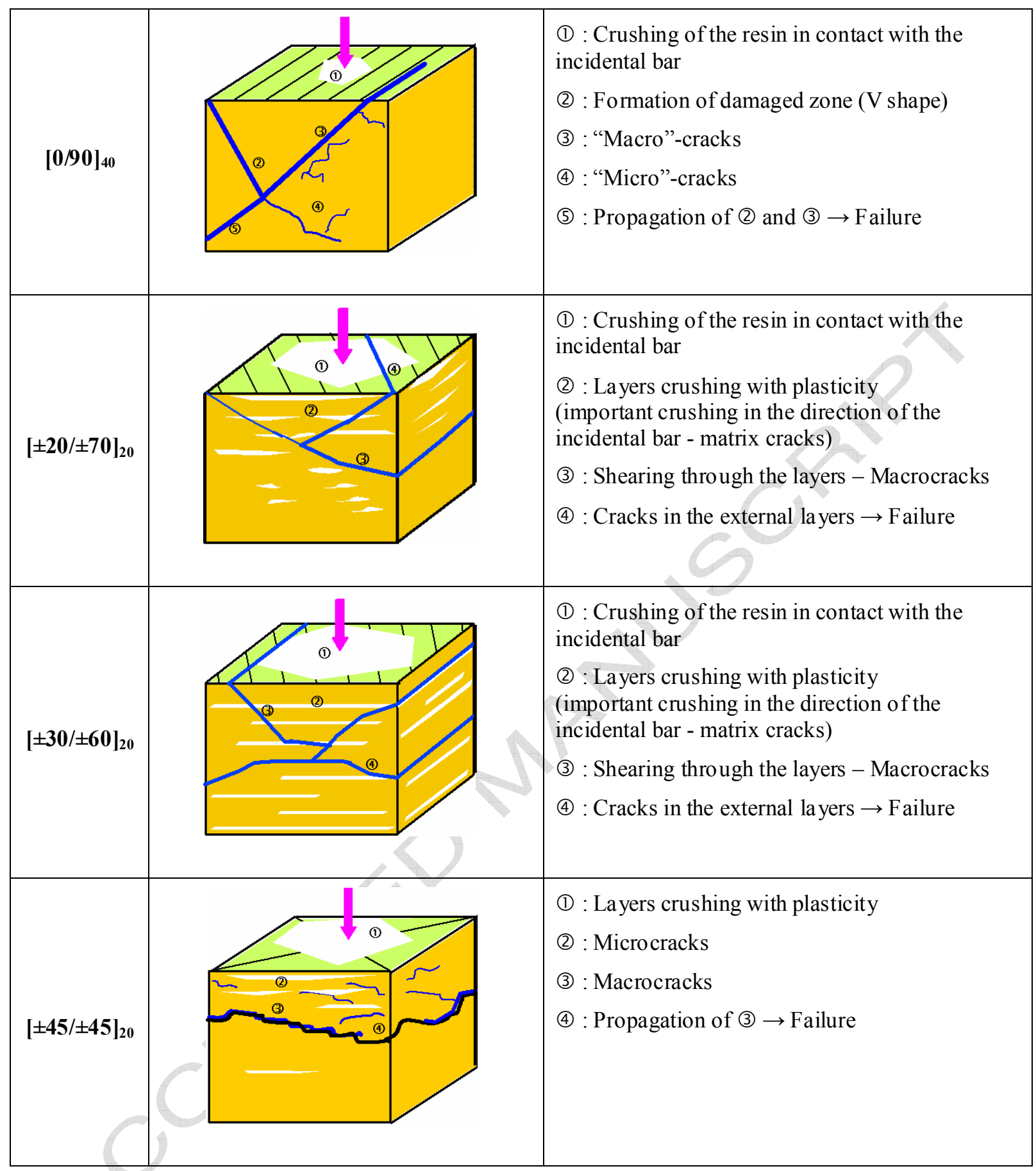

Figure 13. Damaging modes for OP tests 